\title{
Is off-pump coronary artery bypass grafting superior to conventional bypass in octogenarians?
}

\author{
Damien J. LaPar, MD, ${ }^{a}$ Castigliano M. Bhamidipati, DO, ${ }^{a}$ T. Brett Reece, MD, ${ }^{b}$ Joseph C. Cleveland, MD, ${ }^{b}$ \\ Irving L. Kron, MD, ${ }^{a}$ and Gorav Ailawadi, $\mathrm{MD}^{\mathrm{a}}$
}

\begin{abstract}
Objective: Selected patients appear to benefit from off-pump coronary artery bypass compared with conventional coronary artery bypass with cardiopulmonary bypass. It is unknown whether elderly patients undergoing isolated coronary artery bypass grafting operations derive any benefit when performed off-pump. We hypothesized that off-pump coronary bypass offers a greater operative benefit to elderly patients when compared with conventional coronary artery bypass.
\end{abstract}

Methods: A total of 1993 elderly patients (age $\geq 80$ years) underwent isolated, primary coronary artery bypass graft operations at 16 different statewide centers from 2003 to 2008. Patients were stratified into 2 groups: conventional coronary artery bypass $(n=1589$, age $=82.5 \pm 2.4$ years $)$ and off-pump bypass $(n=404$, age $=83.0 \pm$ 2.4 years). Preoperative risk, intraoperative findings, postoperative complications, and costs were evaluated.

Results: Patients undergoing off-pump bypass grafting were marginally older $(P=.001)$ and had higher rates of preoperative atrial fibrillation $(14.6 \%$ vs $10.0 \% ; P=.01)$ and New York Heart Association class IV heart failure $(29.7 \%$ vs $21.1 \% ; P<.001)$ than did those having conventional coronary bypass grafting. Other patient risk factors and operative variables, including Society of Thoracic Surgeons predicted risk of mortality, were similar in both groups $(P=.15)$. Compared with off-pump bypass, conventional coronary bypass incurred higher blood transfusion rates $(2.0 \pm 1.7$ units vs $1.6 \pm 1.9$ units; $P=.05)$ as well as more postoperative atrial fibrillation $(28.4 \%$ vs $21.5 \% ; P=.003)$, prolonged ventilation $(14.7 \%$ vs $11.4 \% ; P=.05)$, and major complications $(20.1 \%$ vs $15.6 \% ; P=.04)$. Importantly, postoperative stroke $(2.6 \%$ vs $1.7 \% ; P=.21)$, renal failure $(8.1 \%$ vs $6.2 \% ; P=.12)$, and postoperative length of stay $(P=.41)$ were no different between groups. Despite more complications in patients having conventional bypass, operative mortality $(P=.53)$ and hospital costs ( $P=.43)$ were similar to those of patients having off-pump procedures.

Conclusions: Performance of coronary artery bypass grafting among octogenarian patients is safe and effective. Off-pump coronary artery bypass confers shorter postoperative ventilation but equivalent mortality to conventional coronary artery bypass. Off-pump coronary artery bypass was associated with a reduction in the composite incidence of major complications in unadjusted and adjusted analyses and should be considered an acceptable alternative to conventional bypass for myocardial revascularization in elderly patients. ( $\mathrm{J}$ Thorac Cardiovasc Surg 2011;141:81-90)

The increasing performance of off-pump coronary artery bypass grafting (OPCAB) within certain centers reflects surgeon preference to avoid the inherent risks of cardiopul-

From the Department of Surgery, ${ }^{a}$ Division of Thoracic and Cardiovascular Surgery, University of Virginia Health System, Charlottesville, Va; and the Department of Surgery, ${ }^{b}$ Division of Cardiothoracic Surgery, University of Colorado-Denver, Aurora, Colo.

Supported by Award No. 2T32HL007849-11A1 (to D.L., C.B.) from the National Heart, Lung, and Blood Institute and the Thoracic Surgery Foundation for Research and Education Research Grant (to G.A.). The content is solely the responsibility of the authors and does not necessarily represent the official views of the National Heart, Lung, and Blood Institute or the National Institutes of Health.

Disclosures: Authors have nothing to disclose with regard to commercial support.

Read at the 36th Annual Meeting of The Western Thoracic Surgical Association,

Ojai, California, June 23-26, 2010.

Received for publication June 26, 2010; revisions received Aug 31, 2010; accepted for publication Sept 19, 2010; available ahead of print Nov 8, 2010.

Address for reprints: Gorav Ailawadi, MD, PO Box 800679, Charlottesville, VA 22908-0679 (E-mail: gorav@virginia.edu).

$0022-5223 / \$ 36.00$

Copyright (c) 2011 Published by Elsevier Inc. on behalf of The American Association for Thoracic Surgery

doi:10.1016/j.jtcvs.2010.09.012 monary bypass (CPB) and cardioplegic arrest including hemodilution, nonpulsatile arterial flow, global myocardial ischemia, atherosclerotic embolization from aortic manipulation, and systemic inflammatory response. According to the Society of Thoracic Surgeons (STS) National Adult Cardiac Surgery Database, more than 163,000 isolated coronary artery bypass grafting operations were performed in 2009 , of which OPCAB accounted for just over 34,000 $(20.8 \%) .{ }^{1}$ These trends reflect a variety of motivators, including surgeon and patient preference, patient risk, and the perceived benefits of OPCAB compared with conventional coronary artery bypass grafting with $\mathrm{CPB}$ (CABG).

Selected groups of patients appear to benefit from OPCAB compared with conventional CABG. In a large observational study, OPCAB has been shown to benefit patients requiring high-risk cardiac surgery (STS predicted risk of mortality $>2.5 \%$ ) over conventional $\mathrm{CABG}^{2}$ In addition, patients with an acute ST-elevation myocardial infarction, patients with renal insufficiency, those with 


\author{
Abbreviations and Acronyms \\ CABG $=$ coronary artery bypass grafting with \\ cardiopulmonary bypass \\ $\mathrm{CPB}=$ cardiopulmonary bypass \\ ITA $=$ internal thoracic artery \\ NYHA $=$ New York Heart Association \\ $\mathrm{OPCAB}=$ off-pump coronary artery bypass \\ grafting \\ PRBC $=$ packed red blood cell \\ PROM $=$ predicted risk of mortality \\ STS = Society of Thoracic Surgeons \\ VCSQI = Virginia Cardiac Surgery Quality \\ Initiative
}

cerebrovascular disease, and women appear to have better outcomes with OPCAB than with conventional CABG. With a rising elderly cardiac surgical population, ${ }^{3}$ outcomes in patients with advanced age need critical evaluation. Several series have documented cardiac surgical outcomes among elderly patients with varying results. ${ }^{3-6}$ It is unknown whether elderly patients undergoing isolated $\mathrm{CABG}$ operations derive any benefit when performed offpump.

The objective of this study was to examine the effect of performing $\mathrm{OPCAB}$ within octogenarians. We hypothesized that OPCAB offers a greater operative benefit to elderly patients with respect to operative risk, postoperative morbidity, and total costs than does conventional CABG.

\section{PATIENTS AND METHODS \\ Patients}

Owing to the absence of patient identifiers within the Virginia Cardiac Surgery Quality Initiative (VCSQI) database and the fact that the data are collected for purposes other than research, data analyses were exempt from the University of Virginia Institutional Review Board. In addition, participating institutions were exempt from Health Insurance Portability and Accountability Act consideration by the use of the Small Business Agreement for Business Associates agreements between each hospital and participating surgeons. The VCSQI is a voluntary consortium of 16 different cardiac surgical centers and hospitals within the Commonwealth of Virginia that, collectively, captures approximately $99 \%$ of Virginia's cardiac surgical procedures. All CABG operations were entered prospectively into the National STS Adult Cardiac Surgery Database by participating VCSQI centers. Long-term follow-up beyond 30 days, like the STS Database, is not collected in the VCSQI. We retrospectively reviewed all patients undergoing primary, isolated coronary artery bypass grafting operations as reported by the VCSQI from January 2003 to December 2008. Primary operations were those occurring in the absence of a prior sternotomy or cardiac operation. Patients were stratified into 2 study groups according to the use of $\mathrm{CPB}$ : conventional coronary artery bypass grafting with $\mathrm{CPB}(\mathrm{CABG})$ and off-pump coronary artery bypass grafting (OPCAB).

Patient risk factors, operative features, postoperative outcomes, and total hospital costs were evaluated. We used established STS definitions for all patient variables and postoperative outcomes. ${ }^{7}$ Operative mortality in- cluded in-hospital death during the same admission or within 30 days of operation. Major complications included the composite incidence of postoperative stroke, renal failure, prolonged ventilation, pneumonia, and myocardial infarction. Total hospital costs were estimated calculations as reported by the VCSQI.

\section{Statistical Analysis}

All outcomes analyzed in this study were established a priori to reduce the potential for type I error. The primary outcomes of interest were operative mortality and major complication rate, and secondary outcomes included postoperative length of stay and total costs. All group comparisons were unpaired. Continuous variables were compared using analysis of variance, and categorical variables were compared using $\chi^{2}$ analysis or Fisher's exact tests as appropriate.

Multivariable logistic regression was performed to assess the independent effects of known preoperative risk factors on the odds of operative mortality and postoperative complication rates between both CABG and OPCAB groups. All preoperative variables entered as covariates (age, sex, preoperative renal failure, stroke, atrial fibrillation, New York Heart Association [NYHA] class, elective operative status, ejection fraction, left main coronary occlusion $>50 \%$, intraoperative packed red blood cell $[\mathrm{PRBC}]$ transfusion, and performance of $\mathrm{OPCAB}$ ) were selected a priori on the basis of established clinical risk during $\mathrm{CABG}$ operations before data analysis. The estimated odds of morbidity and mortality were adjusted for all covariates. The discrimination achieved by these models was assessed using the area under the receiver operating characteristics curve. Values of 1.0 for the area under the receiver operating characteristics curve indicate perfect discrimination between outcome groups, whereas values of 0.5 indicate results equal to chance. Model calibration across deciles of observed and predicted risk was assessed using the Hosmer-Lemeshow test.

Categorical variable comparisons are expressed as a percentage of the group of origin. Continuous variables are reported as means \pm standard deviation. Odds ratios with a $95 \%$ confidence interval are used to report the results of logistic regression models. Reported $P$ values are 2-tailed. Data manipulation and analysis were performed with SPSS software, version 17 (SPSS, Inc, Chicago, Ill).

\section{RESULTS}

\section{Patient Risk Factors and Operative Features}

A total of 1993 octogenarian ( $\geq 80$ years old) patients underwent primary, isolated coronary artery bypass grafting operations in Virginia during the 6-year study period: CABG $(n=1589)$ and OPCAB $(n=404)$. All patient demographics, preoperative risk factors, and operative features are presented in Table 1. Study cohorts were well matched with respect to patient comorbid disease and preoperative risk. Average STS predicted risk of mortality (PROM) was $5.7 \% \pm 7.1 \%$ for patients having conventional $\mathrm{CABG}$ and $6.3 \% \pm 6.9 \%$ for those having $\mathrm{OPCAB}$ $(P=.15)$, and the incidence of left main coronary artery occlusion of $50 \%$ or more was similar between groups. OP$\mathrm{CAB}$ patients were marginally older than CABG patients with higher incidence of preoperative stroke, NYHA class IV functional status, and atrial fibrillation. CABG patients had a higher incidence of 3-vessel or greater coronary disease. Overall, internal thoracic artery (ITA) use was more common among OPCAB operations $(P<.001)$, and OPCAB $(89.4 \%$ vs $81.4 \% ; P<.001)$ patients underwent a higher percentage of left ITA anastomoses. A higher 
TABLE 1. Patient demographics, preoperative risk factors, and operative features for all patients undergoing primary, isolated coronary artery bypass grafting operations

\begin{tabular}{|c|c|c|c|}
\hline Variable & $\begin{array}{c}\text { CABG } \\
(\mathbf{n}=1589) \\
\end{array}$ & $\begin{array}{c}\text { OPCAB } \\
(n=404)\end{array}$ & $P$ value \\
\hline \multicolumn{4}{|l|}{ Preoperative } \\
\hline Age at operation (y) & $82.5 \pm 2.4$ & $83.0 \pm 2.4$ & $<.001$ \\
\hline Female gender & $38.6 \%$ & $42.1 \%$ & .11 \\
\hline Peripheral vascular disease & $18.9 \%$ & $19.6 \%$ & .40 \\
\hline Stroke & $8.3 \%$ & $11.6 \%$ & .03 \\
\hline Diabetes & $30.5 \%$ & $27.2 \%$ & .11 \\
\hline Dyslipidemia & $73.4 \%$ & $60.9 \%$ & $<.001$ \\
\hline Hypertension & $83.9 \%$ & $81.2 \%$ & .11 \\
\hline \multicolumn{4}{|l|}{ NYHA class } \\
\hline Class I & $13.2 \%$ & $6.2 \%$ & $<.001$ \\
\hline Class II & $22.3 \%$ & $22.0 \%$ & \\
\hline Class III & $43.5 \%$ & $42.1 \%$ & \\
\hline Class IV & $21.1 \%$ & $29.7 \%$ & \\
\hline Heart failure & $13.5 \%$ & $18.9 \%$ & .20 \\
\hline Atrial fibrillation & $10.0 \%$ & $14.6 \%$ & .01 \\
\hline Endocarditis & $0.0 \%$ & $0.0 \%$ & N/A \\
\hline Renal failure & $5.8 \%$ & $7.4 \%$ & .14 \\
\hline $\begin{array}{l}\text { Renal failure } \\
\text { (hemodialysis) }\end{array}$ & $1.0 \%$ & $1.5 \%$ & .28 \\
\hline \multicolumn{4}{|c|}{ No. of major arteries with stenosis $>50 \%$} \\
\hline 1 & $2.1 \%$ & $16.2 \%$ & $<.001$ \\
\hline 2 & $13.9 \%$ & $30.2 \%$ & \\
\hline 3 & $84.0 \%$ & $53.6 \%$ & \\
\hline Left main stenosis $>50 \%$ & $38.6 \%$ & $36.9 \%$ & .53 \\
\hline STS PROM $(\%)$ & $5.7 \pm 7.1$ & $6.3 \pm 6.9 \%$ & .15 \\
\hline \multicolumn{4}{|l|}{ Operative } \\
\hline Elective & $38.3 \%$ & $40.3 \%$ & .87 \\
\hline Urgent & $57.3 \%$ & $54.7 \%$ & \\
\hline Emergency & $4.3 \%$ & $5.0 \%$ & \\
\hline Crossclamp time (min) & $63.9 \pm 23.8$ & - & - \\
\hline Bypass time (min) & $92.2 \pm 34.0$ & - & - \\
\hline Total no. of bypass grafts & $3.4 \pm 0.02$ & $2.2 \pm 0.07$ & $<.001$ \\
\hline Overall ITA use & $82.3 \%$ & $91.9 \%$ & $<.001$ \\
\hline LITA & $81.4 \%$ & $89.4 \%$ & \\
\hline RITA & $0.3 \%$ & $0.0 \%$ & \\
\hline Bilateral ITA & $0.4 \%$ & $2.1 \%$ & \\
\hline \multicolumn{4}{|c|}{ Distal arterial anastomosis (no.) } \\
\hline 1 & $75.7 \%$ & $84.6 \%$ & .01 \\
\hline 2 & $4.6 \%$ & $6.0 \%$ & \\
\hline 3 & $1.2 \%$ & $0.9 \%$ & \\
\hline$>4$ & $0.6 \%$ & $0.4 \%$ & \\
\hline \multicolumn{4}{|l|}{ Distal vein anastomosis (no.) } \\
\hline 0 & $3.2 \%$ & $31.1 \%$ & $<.001$ \\
\hline 1 & $10.6 \%$ & $28.2 \%$ & \\
\hline 2 & $39.5 \%$ & $29.1 \%$ & \\
\hline 3 & $33.9 \%$ & $10.7 \%$ & \\
\hline$>4$ & $12.8 \%$ & $0.9 \%$ & \\
\hline
\end{tabular}

number of total grafts $(P=.001)$ were used in CABG operations than in OPCAB. OPCAB operations included a higher frequency of arterial anastomoses $(P=.01)$,
TABLE 1. Continued

\begin{tabular}{lccc}
\hline Variable & $\begin{array}{c}\text { CABG } \\
(\mathbf{n}=\mathbf{1 5 8 9})\end{array}$ & $\begin{array}{c}\text { OPCAB } \\
(\mathbf{n}=\mathbf{4 0 4})\end{array}$ & $\boldsymbol{P}$ value \\
\hline Radial artery anastomosis (no.) & & & \\
1 & $4.1 \%$ & $4.0 \%$ & .14 \\
2 & $4.1 \%$ & $0.0 \%$ & \\
3 & $1.2 \%$ & $0.0 \%$ & \\
PRBC transfusion (units) & $2.0 \pm 1.7$ & $1.6 \pm 1.0$ & .05 \\
\hline CABG, Conventional coronary artery bypass grafting; $O P C A B$, off-pump coronary \\
artery bypass grafting; $N Y H A$, New York Heart Association; $S T S$, Society of Thoracic \\
Surgery; $P R O M$, predicted risk of mortality ITA, internal thoracic artery; $L I T A$, left \\
internal thoracic artery; RITA, right internal thoracic artery; $P R B C$, packed red blood \\
cell; $N / A$, not applicable.
\end{tabular}

whereas $\mathrm{CABG}$ operations included more vein graft anastomoses $(P<.001)$. Importantly, operative status (elective, urgent, emergency) was similar between study groups.

\section{Unadjusted Outcomes for Conventional CABG and OPCAB}

Postoperative outcomes for octogenarian patients undergoing conventional $\mathrm{CABG}$ and $\mathrm{OPCAB}$ operations are presented in Table 2. Patients undergoing conventional CABG accrued higher intraoperative transfusion requirements. Compared with OPCAB, conventional CABG incurred more postoperative atrial fibrillation $(28.4 \%$ vs $21.5 \%$; $P=.003)$, prolonged ventilation $(14.7 \%$ vs $11.4 \%$; $P=.05)$, and major complications $(P=.04)$ (Figure 1$)$. Importantly, postoperative stroke $(2.6 \%$ vs $1.7 \% ; P=.21)$ and renal failure $(8.1 \%$ vs $6.2 \% ; P=.12)$ rates were no different between groups. Despite more complications in CABG patients, operative mortality was similar after both CABG $(5.1 \%)$ and $\mathrm{OPCAB}(5.9 \% ; P=.53)$ operations. Moreover, patients had similar total hospital $(P=.75)$ and postoperative $(P=.41)$ lengths of stay as well as similar total costs $(P=.43)$.

\section{Factors Related to Mortality in Patients Undergoing Conventional CABG and OPCAB}

Univariate analyses of all preoperative and operative risk factors are listed for all survivors and decedents after both conventional CABG and OPCAB operations in Table 3. Among conventional CABG operations, mortality was more frequent in women, those with NYHA class IV status, heart failure, lower ejection fraction, and preoperative atrial fibrillation. Decedents expectedly had higher STS PROM and underwent a higher percentage of nonelective operations with longer $\mathrm{CPB}$ times.

Among OPCAB patients, decedents more commonly had higher NYHA class, preoperative hemodialysis requirements, higher STS PROM, and underwent more emergency operations than did survivors. In contrast to those undergoing conventional $\mathrm{CABG}$, female gender was not associated 
TABLE 2. Unadjusted postoperative outcomes for all patients undergoing primary, isolated coronary artery bypass grafting operations

\begin{tabular}{|c|c|c|c|}
\hline Outcome & $\begin{array}{c}\text { CABG } \\
(\mathbf{n}=\mathbf{1 5 8 9}) \\
\end{array}$ & $\begin{array}{c}\text { OPCAB } \\
(n=404)\end{array}$ & $\begin{array}{r}P \\
\text { value }\end{array}$ \\
\hline Sepsis & $1.4 \%$ & $0.7 \%$ & .22 \\
\hline Stroke & $2.6 \%$ & $1.7 \%$ & .21 \\
\hline Myocardial infarction & $0.3 \%$ & $1.2 \%$ & .03 \\
\hline Cardiac arrest & $2.6 \%$ & $1.7 \%$ & .21 \\
\hline $\begin{array}{l}\text { Reoperation for graft } \\
\text { occlusion }\end{array}$ & $0.1 \%$ & $0.0 \%$ & .64 \\
\hline Atrial fibrillation & $28.4 \%$ & $21.5 \%$ & .003 \\
\hline Gastrointestinal event & $3.3 \%$ & $3.2 \%$ & .55 \\
\hline Pneumonia & $5.0 \%$ & $5.0 \%$ & .55 \\
\hline Prolonged ventilation & $14.7 \%$ & $11.4 \%$ & .05 \\
\hline Renal failure & $8.1 \%$ & $6.2 \%$ & .12 \\
\hline Hemodialysis & $3.1 \%$ & $2.5 \%$ & .30 \\
\hline ICU LOS (h) & $101.3 \pm 173.0$ & $84.8 \pm 110.8$ & .21 \\
\hline Postoperative LOS (d) & $9.04 \pm 10.0$ & $9.52 \pm 10.5$ & .41 \\
\hline Hospital LOS (d) & $12.39 \pm 11.1$ & $12.20 \pm 10.6$ & .75 \\
\hline Major complication & $20.1 \%$ & $15.6 \%$ & .04 \\
\hline Operative mortality & $5.1 \%$ & $5.9 \%$ & .53 \\
\hline $\begin{array}{r}\text { Readmission } \\
<30 \text { days }\end{array}$ & $9.7 \%$ & $10.6 \%$ & .31 \\
\hline ICU/CCU cost (\$) & $8,826.70 \pm 11,564.90$ & $7,645.16 \pm 7,845.56$ & .08 \\
\hline Total cost $(\$)$ & $\begin{array}{r}36,755.18 \pm \\
34,650.30\end{array}$ & $\begin{array}{r}35,030.55 \pm \\
34,634.70\end{array}$ & .43 \\
\hline
\end{tabular}

Boldface indicates statistically significant $P$ values. $C A B G$, Conventional coronary artery bypass grafting; $O P C A B$, off-pump coronary artery bypass grafting; $I C U$, intensive care unit; $L O S$, length of stay; $C C U$, cardiac care unit.

with mortality in patients undergoing $\mathrm{OPCAB}$ according to univariate analysis.

There were several different causes for mortality among those undergoing coronary artery bypass grafting operations (Figure 2). Overall, the most common primary cause of patient mortality was cardiac in origin $(47.6 \%)$, followed by pulmonary $(17.1 \%)$ and neurologic $(10.5 \%)$ etiologies. Renal causes accounted for $5.7 \%$ of patient mortality whereas infections were responsible for $4.8 \%$ of deaths.

\section{Risk-Adjusted Mortality and Morbidity}

Risk-adjusted odds ratios and multivariable logistic regression results for operative mortality among all octogenarian patients undergoing coronary bypass operations are displayed in Table 4. Operative mortality was associated with female gender, preoperative atrial fibrillation, presence of left main coronary artery occlusion of $50 \%$ or more, and degree of intraoperative PRBC transfusion. An increase in the odds of mortality was associated with performance of urgent/emergency operations and depressed ventricular function. Importantly, performance of OPCAB among octogenarians was not an independent predictor of operative mortality $(P=.87)$.

Multivariable logistic regression revealed similar results for risk-adjusted postoperative complication rates among

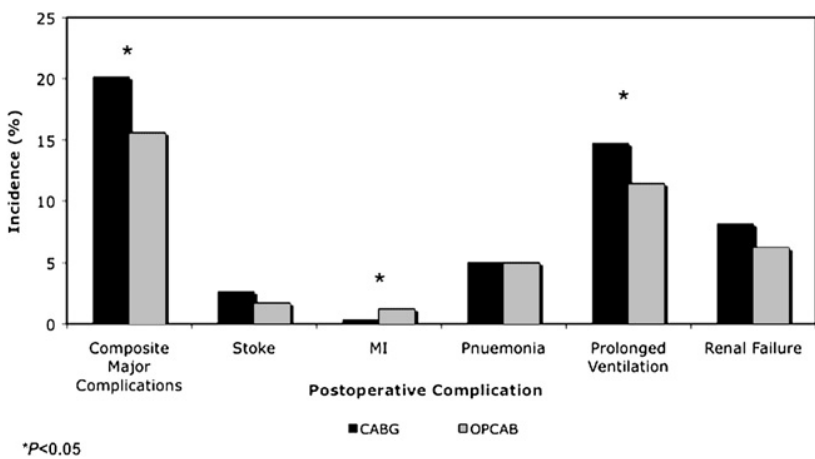

FIGURE 1. Incidence of postoperative outcomes contributing to composite incidence of major complications for patients undergoing primary, isolated $\mathrm{CABG}$ or OPCAB operations. $M I$, Myocardial infarction; $C A B G$, conventional coronary artery bypass grafting; $O P C A B$, off-pump coronary artery bypass grafting.

octogenarians (Table 4). Within the model for any postoperative complication, patient age and preoperative renal failure independently increased the odds of a postoperative complication. In contrast, urgent/emergency operative status and depressed ventricular function increased the odds of complications. Similar trends were observed for the model constructed for the composite outcome of major complication rate. Importantly, performance of OPCAB was associated with decreased odds of any postoperative complication (odds ratio $=0.74[0.59-0.93] ; P=.01$ ) or major complication (odds ratio $=0.68[0.50-0.93] ; P=.02$ ) compared with the performance of a conventional CABG.

\section{DISCUSSION}

This study adds to the mounting body of evidence examining the comparative effectiveness of conventional onpump versus off-pump coronary revascularization among select patient populations, and it highlights the short-term morbidity benefits of OPCAB among octogenarian patients. Within this large, multi-institutional patient cohort, OP$\mathrm{CAB}$ was performed in $20 \%$ of cases, which is similar to nationwide trends. Operative mortality rates were comparable between both conventional CABG (5.1\%) and OPCAB $(5.9 \% ; P=.29)$ groups. We similarly demonstrated equivalent intensive care unit and hospital lengths of stay as well as total hospital costs for both study groups. Importantly, as documented in other studies, we demonstrated reduced intraoperative transfusion requirements, lower postoperative atrial fibrillation rates, decreased prolonged ventilation, and lower major complication rates after OPCAB. Moreover, performance of OPCAB compared with CABG significantly decreased risk-adjusted postoperative complication rates by $26 \%$ and major complication rates by $32 \%$ on multivariable logistic regression. These results corroborate arguments for the safety and beneficial effects of OPCAB compared with $\mathrm{CPB}$ use during surgical, myocardial revascularization. 
TABLE 3. Univariate comparisons of patient and operation-related risk factors for survivors and decedents undergoing primary, isolated coronary artery bypass grafting operations

\begin{tabular}{|c|c|c|c|c|c|c|}
\hline \multirow[b]{2}{*}{ Variable } & \multicolumn{3}{|c|}{ CABG $(n=1589)$} & \multicolumn{3}{|c|}{ OPCAB $(n=404)$} \\
\hline & Survivors $(\mathrm{n}=1508)$ & Decedents $(n=81)$ & $P$ value & Survivors $(n=221)$ & Decedents $(n=13)$ & $P$ value \\
\hline \multicolumn{7}{|l|}{ Preoperative } \\
\hline Age at operation (y) & $82.5 \pm 0.07$ & $82.6 \pm 0.14$ & .09 & $83.0 \pm 0.13$ & $83.1 \pm 0.34$ & .27 \\
\hline Female gender & $37.5 \%$ & $59.3 \%$ & $<.001$ & $41.8 \%$ & $45.8 \%$ & .83 \\
\hline Peripheral vascular disease & $18.5 \%$ & $25.9 \%$ & .11 & $18.7 \%$ & $33.3 \%$ & .11 \\
\hline Stroke & $8.5 \%$ & $4.9 \%$ & .41 & $11.6 \%$ & $12.5 \%$ & .75 \\
\hline Diabetes & $30.1 \%$ & $37.0 \%$ & .22 & $27.1 \%$ & $29.2 \%$ & .82 \\
\hline Dyslipidemia & $73.3 \%$ & $75.3 \%$ & .79 & $60.3 \%$ & $70.8 \%$ & .39 \\
\hline Hypertension & $83.6 \%$ & $90.1 \%$ & .16 & $80.8 \%$ & $87.5 \%$ & .59 \\
\hline \multicolumn{7}{|l|}{ NYHA class } \\
\hline Class I & $13.2 \%$ & $12.3 \%$ & .39 & $6.3 \%$ & $4.2 \%$ & .04 \\
\hline Class II & $22.5 \%$ & $18.5 \%$ & & $23.2 \%$ & $4.2 \%$ & \\
\hline Class III & $43.8 \%$ & $37.0 \%$ & & $42.6 \%$ & $33.3 \%$ & \\
\hline Class IV & $20.5 \%$ & $32.1 \%$ & & $27.9 \%$ & $58.3 \%$ & \\
\hline Heart failure & $16.2 \%$ & $29.6 \%$ & .003 & $18.7 \%$ & $21.7 \%$ & .78 \\
\hline Atrial fibrillation & $9.2 \%$ & $24.7 \%$ & $<.001$ & $14.5 \%$ & $16.7 \%$ & .77 \\
\hline Endocarditis & $0.0 \%$ & $0.0 \%$ & N/A & $0.0 \%$ & $0.0 \%$ & N/A \\
\hline Renal failure & $5.4 \%$ & $12.3 \%$ & .02 & $7.4 \%$ & $8.3 \%$ & .70 \\
\hline Hemodialysis & $1.0 \%$ & $1.2 \%$ & .57 & $1.1 \%$ & $8.3 \%$ & .04 \\
\hline Ejection fraction $(\%)$ & $51.1 \pm 12.7$ & $45.8 \pm 15.4$ & $<.001$ & $51.4 \pm 12.4$ & $48.4 \pm 11.1$ & .27 \\
\hline STS PROM (\%) & $5.16 \pm 4.89$ & $15.82 \pm 20.8$ & $<.001$ & $5.80 \pm 6.21$ & $14.0 \pm 11.7$ & $<.001$ \\
\hline \multicolumn{7}{|l|}{ Operative } \\
\hline Elective & $39.3 \%$ & $21.0 \%$ & $<.001$ & $41.6 \%$ & $20.8 \%$ & .001 \\
\hline Urgent & $57.2 \%$ & $58.0 \%$ & & $54.5 \%$ & $58.3 \%$ & \\
\hline Emergency & $3.4 \%$ & $21.0 \%$ & & $3.9 \%$ & $20.8 \%$ & \\
\hline Crossclamp time (min) & $63.8 \pm 23.6$ & $64.7 \pm 27.7$ & .74 & N/A & N/A & N/A \\
\hline Bypass time (min) & $91.5 \pm 33.4$ & $104.9 \pm 41.8$ & $<.001$ & N/A & N/A & N/A \\
\hline PRBC transfusion (units) & $1.97 \pm 0.03$ & $2.46 \pm 0.17$ & .16 & $1.93 \pm 0.02$ & $1.94 \pm 1.0$ & .16 \\
\hline
\end{tabular}

Boldface indicates statistically significant $P$ values. $C A B G$, Conventional coronary artery bypass grafting; $O P C A B$, off-pump coronary artery bypass grafting; $N Y H A$, New York Heart Association; STS, Society of Thoracic Surgeons; PROM, predicted risk of mortality; PRBC, packed red blood cell; N/A, not available.

Cardiac surgery among octogenarian and other elderly patients has been increasingly emphasized in recent literature. Several series have reported longer hospital stays as well as increased morbidity and mortality among octogenarian patients after cardiac operations. ${ }^{8-10}$ Worse survival seen among octogenarians has been attributed to the higher prevalence of complex comorbid disease in elderly patients. ${ }^{8-10}$ Further, increasing evidence suggests that a combination of intraoperative factors, including CPB time, transfusion requirements, and left ITA revascularization, are important determinants of survival among octogenarians undergoing coronary artery bypass grafting, contributing to an $8 \%$ to $12 \%$ operative mortality rate among these patients. ${ }^{9,11,12}$ In this series, the $5.3 \%$ overall mortality rate and relatively low incidence of postoperative complications compare favorably and may be due to factors related to patient selection. In addition, our results suggest that overall outcomes after coronary artery bypass grafting operations within octogenarians have improved in recent times and that surgical myocardial revascularization can be performed safely and with acceptable operative risk.
Over the past few decades, resurgence in the popularity of OPCAB has occurred throughout North and South America, and comparisons documenting the potential benefits and pitfalls of CPB use have varied. Several randomized controlled trials have been performed to assess outcomes for OPCAB compared with CABG with mixed results. In the Octopus trial, no significant differences in perioperative morbidity or mortality were reported for $\mathrm{CABG}$ versus $\mathrm{OPCAB}$ in a cohort of 281 patients, but reductions in duration of mechanical ventilation and hospital stay were noted. ${ }^{13}$ Similarly, Puskas and colleagues ${ }^{14}$ demonstrated equivalent inhospital and 30-day outcomes for OPCAB as well as similar complete revascularization rates, shorter lengths of say, reduced transfusion requirements, and less myocardial injury. Recently, Angelini and colleagues ${ }^{15}$ reported long-term results for 2 randomized controlled trials, demonstrating equivalent long-term (6-8 years) outcomes despite the use of CPB among experienced OPCAB surgeons. These results are in direct contrast to those reported in the recent randomized on/off bypass (ROOBY) trial, which demonstrated equivalent short-term (30-day) outcomes for CABG and OPCAB operations, but reported worse long-term (1 year) 


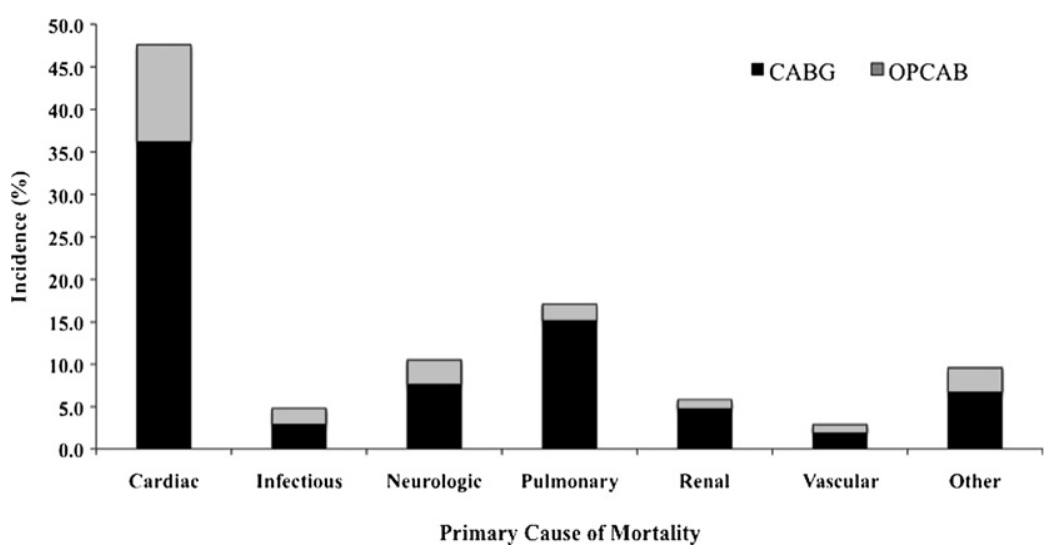

FIGURE 2. Incidence of primary cause of mortality for decedents after isolated CABG or OPCAB operations. $C A B G$, Conventional coronary artery bypass grafting; $O P C A B$, off-pump coronary artery bypass grafting.

composite outcomes, completeness of revascularization, and graft patency for OPCAB. ${ }^{16}$ Similarly, a recent meta-analysis also suggested worse long-term graft patency rates among OPCAB operations. ${ }^{17}$ Alternatively, several meta-analyses and large observational studies have reported equivalent and, in some cases, improved surgical outcomes for the performance of OPCAB over conventional CABG. ${ }^{18-22}$ The variance in reported outcomes within available literature highlights the unsettled debate regarding the success of OPCAB versus $\mathrm{CABG}$. However, the majority of series lacks a significant population of octogenarian patients and includes a relatively low-risk patient cohort. More important, a lack of evidence exists examining the effect of OPCAB within the octogenarian population, and the question of the importance of long-term graft patency within the extreme elderly remains unanswered.

Efforts to identify which surgical populations may benefit from OPCAB over conventional CABG are increasing.
In a large, single-institutional review of more than 11,000 isolated CABG operations, Puskas and colleagues ${ }^{23}$ demonstrated disproportionately improved outcomes for women undergoing OPCAB compared with CABG. Specifically, in this review, women undergoing CABG had $60 \%$ increased odds of death, $71 \%$ increased odds of stroke, and $71 \%$ increased odds for major adverse cardiac events compared with men undergoing CABG; however, this increased risk for women was negated in women undergoing OPCAB. In another recent series, this same group demonstrated that $\mathrm{OPCAB}$ has greatest benefits for high-risk patients, based on STS PROM. ${ }^{2}$ Their analysis of 14,766 primary, isolated CABG operations over a 10 -year period revealed that patients with PROM values greater than $2.5 \%$ derived a significant mortality benefit when undergoing OPCAB compared with CABG. In this study, average patient age was approximately 62 years, and only $38 \%$ of all patients were older than 66 years. As a result, these studies fail to completely demonstrate any advantage of

TABLE 4. Risk-adjusted odds ratios for the effect of selected preoperative and operation-related patient risk factors for the outcomes of operative mortality, any postoperative complication, and major complication rate in elderly patients undergoing coronary artery bypass grafting operations

\begin{tabular}{lccc}
\hline $\begin{array}{c}\text { Preoperative or operative } \\
\text { risk factor }\end{array}$ & Operative mortality & Any complication & Major complications \\
\hline Patient age & $1.06(0.98-1.14)$ & $1.05(1.01-1.09)^{*}$ & $1.02(0.97-1.06)$ \\
Female gender & $2.44(1.60-3.72)^{*}$ & $0.94(0.78-1.14)$ & $1.22(1.13-1.84)^{*}$ \\
Renal failure & $1.82(0.91-3.62)$ & $1.47(0.99-2.19)$ & $2.19(1.43-3.36)^{*}$ \\
Stroke & $0.70(0.32-1.56)$ & $1.16(0.85-1.60)$ & $1.27(0.86-1.88)$ \\
Atrial fibrillation & $2.10(1.26-3.51)^{*}$ & $0.80(0.60-1.07)$ & $1.36(0.96-1.92)$ \\
NYHA class III & $0.87(0.52-1.48)$ & $1.07(0.86-1.33)$ & $1.06(0.79-1.42)$ \\
NYHA class IV & $1.37(0.79-240)$ & $1.29(0.99-1.69)$ & $1.66(1.20-2.31)$ \\
Urgent/emergency operation & $1.43(1.04-1.66)^{*}$ & $1.19(1.01-1.34)^{*}$ & $1.35(1.14-1.50)^{*}$ \\
Ejection fraction & $0.98(0.96-0.99)^{*}$ & $0.99(0.98-0.99)^{*}$ & $0.98(0.98-0.99)^{*}$ \\
Left main disease $>50 \%$ & $1.60(1.06-2.42)^{*}$ & $1.13(0.94-1.37)$ & $1.49(1.17-1.89)^{*}$ \\
OPCAB & $1.04(0.63-1.71)$ & $0.74(0.59-0.93)^{*}$ & $0.68(0.50-0.93)^{*}$ \\
PRBC transfusion (units) & $1.22(1.03-1.44)^{*}$ & $0.99(0.89-1.09)$ & $1.16(1.02-1.32)^{*}$ \\
\hline
\end{tabular}

NYHA, New York Heart Association; $O B C A B$, off-pump coronary artery bypass grafting; $P R B C$, packed red blood cell. $* P<.05$. Results reported as adjusted odds ratios $(95 \%$ confidence interval). All model covariates selected a priori based on established clinical risk before data analyses. 
OPCAB among the truly elderly. In our study population, the documented improvements of OPCAB are not only in agreement with the findings of these 2 previous studies, but further highlight an apparent morbidity benefit of OPCAB for patients older than 80 years of age. Similar to Puskas and associates, ${ }^{23}$ we found that female gender among elderly patients was significantly associated with mortality after CABG operations; however, this disparity disappeared after OPCAB. This association was determined by univariate analyses and was not a product of a statistical interaction on multivariate regression analysis. As a result, this study identifies OPCAB as a safe alternative to CABG in octogenarians and suggests that elderly woman may derive the most benefit from OPCAB. Importantly, however, our results do not suggest that OPCAB provides any additional benefit to elderly patients with preoperative stroke or renal failure.

Several potential explanations exist for our observed results. The performance of conventional CABG in the present study may be due to a surgeon selection bias of more complex patients and could explain the higher morbidity we observed in this group compared with those undergoing OPCAB. Unfortunately, we were unable to account for such selection bias in this retrospective, statewide review. It is, however, important to note that STS PROM was similar between groups with a trend toward a higher risk in OPCAB patients. The influence of prolonged ventilation on the composite incidence of major complications may reflect individual surgeon preference to avoid accelerated extubation in elderly patients or actual detriments of CPB on pulmonary function. In addition, higher transfusion requirements, as seen in multiple other studies, within patients undergoing conventional CABG may have contributed to the higher incidence of prolonged mechanical ventilation in this group as a result of acute lung injury. However, the inclusion of PRBC transfusion requirements in our estimated models likely controlled for the independent influence of this factor on adjusted mortality and complication rates. The discrepancy between the slightly higher morbidity in patients undergoing conventional CABG, despite the similar mortality between groups, may represent the clinical effect of transient, but recoverable, postoperative events on outcomes that can occur during surgery.

Several noteworthy results of this study deserve further discussion. First, higher postoperative myocardial infarction rates were observed for octogenarian OPCAB patients. Unfortunately, owing to the de-identified nature of the VCSQI data set, we were unable to more completely analyze the circumstances of these events. However, these observations are consistent with previously reported inferior long-term graft patency rates for OPCAB operations. ${ }^{16,17}$ However, the effect of better long-term graft patency may or may not be relevant in octogenarians, especially considering these studies do not demonstrate a survival benefit with conventional
CABG. Second, higher ITA use was observed in OPCAB operations in this series and is difficult to explain. Unfortunately, the underlying reason for this observation remains unclear. Lower rates of ITA use may occur in the emergency setting; however, the incidence of emergency operations in this study is similar between the 2 groups.

This study has several limitations to note. The retrospective nature of this study introduced the possibility of inherent selection bias. Additionally, the influence of small, unmeasured differences in patient risk factors between CABG and OPCAB groups may account for some of the differences in observed outcomes. Previously established STS definitions for all outcomes and study variables limited our ability to extrapolate results to a broader patient group. Completely de-identified patient data did not allow us to scrutinize certain data, including conversion rates between $\mathrm{OPCAB}$ and conventional $\mathrm{CABG}$ cohorts, complete versus incomplete myocardial revascularization rates, degree of ascending aortic calcification, or quality of target vessels. Further, as higher PRBC transfusion rates were observed for patients undergoing conventional CABG, we were unable to determine individual institution transfusion protocols to more completely analyze the influence of PRBC transfusion on postoperative outcomes. In addition, our study lacks intermediate or long-term follow-up, and we were only able to comment on short-term outcomes. The estimated cost information provided by the VCSQI was imperfect. Furthermore, the relatively low incidence of operative mortality after CABG operations limited modeling efforts for adjusted outcomes and constrained our efforts for adjust for the potential confounding influence of factors including the number of diseased vessels. Finally, the potential influence of an unmeasured confounder may, in part, explain some of the estimated effects observed between operative groups during logistic regression modeling. Nevertheless, the results of this study provide an important context from which to base future prospective studies.

\section{CONCLUSIONS}

In this study, we conclude that performance of coronary artery bypass grafting among octogenarian patients is safe and effective. Outcomes after both conventional CABG and $\mathrm{OPCAB}$ are similar; however, surgical revascularization without $\mathrm{CPB}$ confers shorter postoperative ventilation requirements. $\mathrm{OPCAB}$ was associated with a reduction in the composite incidence of major complications in unadjusted and adjusted analyses and should be considered an acceptable alternative to conventional CABG for myocardial revascularization in elderly patients.

We thank George J. Stukenborg, PhD, of the University of Virginia Department of Public Health Sciences for his statistical collaboration in this study as well as Eddie Fonner of the ARMUS Corporation for his assistance with data gathering. 


\section{References}

1. Society of Thoracic Surgeons Adult Cardiac Surgery Database. Executive Summary, 4th Harvest. 2009. Available at: http://www.sts.org/documents/pdf/ ndb2010/20094thHarvestExecutiveSummary.pdf.

2. Puskas JD, Thourani VH, Kilgo P, Cooper W, Vassiliades T, Vega JD, et al. Offpump coronary artery bypass disproportionately benefits high-risk patients. Ann Thorac Surg. 2009;88:1142-7.

3. Pierri MD, Capestro F, Zingaro C, Torracca L. The changing face of cardiac surgery patients: an insight into a Mediterranean region. Eur J Cardiothorac Surg. Epub 2010 Apr 15.

4. Craver JM, Puskas JD, Weintraub WW, Shen Y, Guyton RA, Gott JP, et al. 601 octogenarians undergoing cardiac surgery: outcome and comparison with younger age groups. Ann Thorac Surg. 1999;67:1104-10.

5. Ferguson TB Jr, Coombs LP, Peterson ED. Internal thoracic artery grafting in the elderly patient undergoing coronary artery bypass grafting: room for process improvement? J Thorac Cardiovasc Surg. 2002;123:869-80.

6. Johnson WM, Smith JM, Woods SE, Hendy MP, Hiratzka LF. Cardiac surgery in octogenarians: does age alone influence outcomes? Arch Surg. 2005;140: 1089-93.

7. Ngaage DL. Off-pump coronary artery bypass grafting: the myth, the logic and the science. Eur J Cardiothorac Surg. 2003;24:557-70.

8. Likosky DS, Dacey LJ, Baribeau YR, Leavitt BJ, Clough R, Cochran RP, et al. Long-term survival of the very elderly undergoing coronary artery bypass grafting. Ann Thorac Surg. 2008;85:1233-7.

9. Williams DB, Carrillo RG, Traad EA, Wyatt CH, Grahowksi R, Wittels SH, et al. Determinants of operative mortality in octogenarians undergoing coronary bypass. Ann Thorac Surg. 1995;60:1038-43.

10. Alexander KP, Anstrom KJ, Muhlbaier LH, Grosswald RD, Smith PK, Jones RH, et al. Outcomes of cardiac surgery in patients $>$ or $=80$ years: results from the National Cardiovascular Network. J Am Call Cardiol. 2000;35:731-8.

11. Rady MY, Ryan T, Starr NJ. Perioperative determinants of morbidity and mortality in elderly patients undergoing cardiac surgery. Crit Care Med. 1998;26: 225-35.

12. Rohde SL, Baker RA, Tully PJ, Graham S, Cullen H, Knight JL. Preoperative and intraoperative factors associated with long-term survival in octogenarian cardiac surgery patients. Ann Thorac Surg. 2010;89:105-11.

13. van Dijk D, Nierich AP, Jansen EW, Nathoe HM, Suyker WJ, Diephuis JC, et al. Early outcome after off-pump versus on-pump coronary bypass surgery: results from a randomized study. Circulation. 2001;104:1761-6.

14. Puskas JD, Williams WH, Duke PG, Staples JR, Glas KE, Marshall JJ, et al. Offpump coronary artery bypass grafting provides complete revascularization with reduced myocardial injury, transfusion requirements, and length of stay: a prospective randomized comparison of two hundred unselected patients undergoing off-pump versus conventional coronary artery bypass grafting. J Thorac Cardiovasc Surg. 2003;125:797-808.

15. Angelini GD, Culliford L, Smith DK, Hamilton MC, Murphy GJ, Ascione R, et al. Effects of on- and off-pump coronary artery surgery on graft patency, survival, and health-related quality of life: long-term follow-up of 2 randomized controlled trials. J Thorac Cardiovasc Surg. 2009;137:295-303.

16. Shroyer AL, Grover FL, Hattler B, Collins JF, McDonald GO, Kozora E, et al. On-pump versus off-pump coronary-artery bypass surgery. $N$ Engl $\mathrm{J} \mathrm{Med}$. 2009;361:1827-37.

17. Takagi H, Matsui M, Umemoto T. Off-pump coronary artery bypass may increase late mortality: a meta-analysis of randomized trials. Ann Thorac Surg. 2010;89: 1881-8.

18. Cleveland JC Jr, Shroyer AL, Chen AY, Peterson E, Grover FL. Off-pump coronary artery bypass grafting decreases risk-adjusted mortality and morbidity. Ann Thorac Surg. 2001;72:1282-8; discussion 8-9.

19. Puskas JD, Kilgo PD, Lattouf OM, Thourani VH, Cooper WA, Vassiliades TA, et al. Off-pump coronary bypass provides reduced mortality and morbidity and equivalent 10-year survival. Ann Thorac Surg. 2008;86:1139-46; discussion 46.

20. Cheng DC, Bainbridge D, Martin JE, Novick RJ. Does off-pump coronary artery bypass reduce mortality, morbidity, and resource utilization when compared with conventional coronary artery bypass? A meta-analysis of randomized trials. Anesthesiology. 2005;102:188-203.

21. Reston JT, Tregear SJ, Turkelson CM. Meta-analysis of short-term and mid-term outcomes following off-pump coronary artery bypass grafting. Ann Thorac Surg. 2003;76:1510-5.

22. van der Heijden GJ, Nathoe HM, Jansen EW, Grobbee DE. Meta-analysis on the effect of off-pump coronary bypass surgery. Eur J Cardiothorac Surg. 2004;26: 81-4.
23. Puskas JD, Kilgo PD, Kutner M, Pusca SV, Lattouf O, Guyton RA. Off-pump techniques disproportionately benefit women and narrow the gender disparity in outcomes after coronary artery bypass surgery. Circulation. 2007;116(11 Suppl):I192-9.

\section{Discussion}

Dr James I. Fann (Stanford, Calif). I compliment you on a wonderful presentation and a very interesting paper. You and your colleagues are to be congratulated for taking on the challenge of clarifying the outcomes of on-pump (conventional $\mathrm{CABG}$ ) versus off-pump (OPCAB) approach to coronary revascularization in an elderly patient population of nearly 2000 octogenarians over a recent 6-year period.

The distribution of patients undergoing OPCAB was similar to the national average at approximately $20 \%$. Given the retrospective nature of the analysis, the patients were remarkably similar except for age, incidence of preoperative atrial fibrillation, stroke, and the incidence of class IV functional class, all of which were slightly to moderately higher in the OPCAB group. Your analysis showed that despite more postoperative complications in the conventional $C A B G$ group, the operative mortality rates and hospital costs were similar between the groups. Your conclusion that OP$\mathrm{CAB}$ coronary revascularization should be considered as an acceptable alternative to the conventional CABG approach in elderly patients seems to be reasonable, but there are some issues that need to be clarified and may increase the impact regarding previous and potentially future decision-making.

I will limit my questions to 3 main categories. First is the issue of number of grafts. Forty-six percent or nearly half the patients in the OPCAB group had 1- or 2-vessel disease compared with $16 \%$ in the conventional CABG group. Stated another way, $84 \%$ of the patients in the conventional CABG group had 3-vessel disease compared with slightly over half (54\%) in the OPCAB group. Hence, the patient cohorts are different. The question is, how do you think the number of needed grafts affected patient selection and how would you compare this finding of fewer grafts in the $\mathrm{OPCAB}$ group with what others have reported?

Dr LaPar. Thank you very much for those kind comments, Dr Fann. As you identified, clearly there is a selection bias as we concluded in patients who were being selected for OPCAB, and the selection bias does clearly select out patients requiring fewer numbers of grafts and having less multivessel disease. Our data show that and are consistent with what has been reported elsewhere in previous studies as well.

Dr Fann. Second, the incidence of postoperative myocardial infarction was low overall, but this complication was significantly higher in the OPCAB group at $1.2 \%$ compared with $0.3 \%$ in the conventional $\mathrm{CABG}$ cohort. Although this higher incidence might not have affected the overall mortality, it is of concern, and it is important to know the outcome of these 5 patients. For instance, what was the extent of the myocardial infarction? What were the diagnostic criteria for the myocardial infarction? Were the grafts patent? Did any patient require reoperation, percutaneous intervention, or intra-aortic balloon pump placement? How many of these cases were fatal?

Dr LaPar. You are absolutely right. Although we did not present it in this presentation, the perioperative myocardial infarction 
rate was slightly higher within the OPCAB group but statistically significant. As you pointed out, 5 patients within the OPCAB group, that is, 5 of 404 patients, did have postoperative myocardial infarction. Unfortunately, owing to the de-identified nature of our data set, we are unable to completely track out all of the events of that myocardial infarction. However, I can tell you that among those 5 patients, 4 did actually contribute to the operative mortality, so 4 did die. That is, $80 \%$ of that small group of patients did die.

Dr Fann. Third, a major conclusion is that OPCAB confers a lower major complication rate. When assessing the components of the composite score of major complications, prolonged ventilation comprises the bulk of the difference between the 2 groups in terms of major complications. This finding is not surprising given what we know about the effects of CPB. Can you define how long is prolonged? That is, is it 24 hours, 2 days, or 3 days? Regarding this complication, the postoperative length of stay between the 2 groups was similar in this study. Thus it is important to know the definition and significance of prolonged ventilation inasmuch as it really did not appear to have any clinical sequela in terms of length of hospital stay and had no impact on overall cost. Also missing in the preoperative assessment is the incidence of chronic obstructive pulmonary disease. Is it possible that the conventional $\mathrm{CABG}$ group had a higher incidence of pulmonary disease, thereby accounting for the difference in the prolonged ventilation?

Dr LaPar. I think you are absolutely right in that when we break down the composite components of major complications, the highest component of that and the biggest contributor was prolonged ventilation. Prolonged ventilation in this study was defined by the STS definition as being more than 24 hours of ventilation after surgery. The influence of that on our composite incidence is clear. Postoperative ventilation has been shown in the past, especially within other randomized trials such as the Octopus trial, to be independently influenced by the use of CPB. Although there are many factors that may contribute to prolonged ventilation, I still think that is a valid postoperative complication that does in fact affect patient care. Although in our study we did not demonstrate any true correlation between the prolonged ventilation and prolonged intensive care unit or total hospital length of stay, other studies in the past have shown that prolonged ventilation does in fact contribute to greater resource use and longer patient stays in the hospital. We should definitely try to answer that question more clearly in the future.

Dr John C. Chen (Honolulu, Hawaii). I want to ask you to address the issue of fewer grafts in greater depth. One of the things that we have been raised to believe in is that surgical mortality is important, that to have a live patient is perhaps one of the biggest things we strive for. Our cardiologist colleagues, unfortunately, do not have the same view at times. They are more interested in number of grafts that we implant because they believe that the graft number is important to the patient's outcome. One of the things we are looking at is long-term outcome, 5-year survival, in our cohort of conventional CABG and OPCAB patients. Are you looking at that or do you have any plans to look at that to address questions from our cardiology colleagues?

Dr LaPar. You bring up a very good point. The question of long-term graft patency and number of grafts and completeness of revascularization between conventional CABG and OPCAB and just coronary bypass grafting in general compared with some of our interventional techniques is very important. In this study, unfortunately, we were not able to look at any long-term data because of the de-identified nature of our data set; however, with regard to the question of graft patency and 5-year longterm survival within an extreme elderly population such as the octogenarians, I am not quite sure how well we are going to be able to answer that in even a small multicenter trial. We need to evaluate a very large cohort of patients over a very long period of time to more clearly answer that question, but I certainly am interested in following up and trying to answer that question.

Dr James Douglas (Bellingham, Wash). Thank you, Dr LaPar. That was an excellent study, very well presented. For some time I have had the feeling that in current-day practice of OPCAB surgery, we have been essentially asking the wrong question. I think your study really highlights that. The question is not whether OP$\mathrm{CAB}$ is better than conventional $\mathrm{CABG}$, but rather in which patients is OPCABG better than conventional CABG and vice versa. Being someone who has been a practitioner of OPCAB for quite some time, experience has shown me that not everybody benefits equally. When we try to do randomized studies and include everybody as if they are equally amenable to it, I think we make an error in judgment.

The second question that we have not asked appropriately is, who should be dong OPCAB surgery? It is a different skill set. Like any of the procedures that we do with a different skill set, those who are better at the particular skill set will get better results. Studies have shown that the most improvement with OPCAB surgery has been from those institutions in which the staff has the most personal experience.

The question I would really like to ask, though, is related to a different point. I notice that in your paper, as in so many others, there is a trend toward an improvement in the risk of postoperative stroke in patients with OPCAB, although it did not reach statistical significance. One thing that has been very clear from the literature for many years is that the predominant factor for postoperative stroke is ascending aortic atherosclerosis. Regardless of whether you do OPCAB or conventional CABG, if you do not manage that ascending aorta appropriately you are going to have an increased likelihood of embolization and postoperative stroke. Now CPB probably has a component to contribute to postoperative stroke, but it is not the only one and I do not think it is the major one. Therefore, I do not think it is surprising that the overall incidence was a trend toward it but not absolute. My question revolves around any evidence that you might have from the VCSQI or whether the data are available to determine how people manage the aorta. Would it be feasible to look at the postoperative stroke outcome in the patients who had specific techniques designed to prevent perioperative embolization?

Dr LaPar. Thank you very much for that question. Obviously, patient risk stratification is a very important component in trying to further define which patients are better served by OPCAB, and stroke is one of those things that we need to more clearly identify.

Unfortunately, the VCSQI does not have any long-term data or any sort of data, in fact, that might be able to help us answer how other practicing surgeons in other institutions are managing the ascending aorta or in the preoperative, perioperative, or intraoperative setting in making those decisions. I can speak for our 
institution. In almost every patient in whom we use any sort of $\mathrm{CPB}$, we use primarily aortic ultrasound intraoperatively to survey the cannulation sites or just the ascending aorta in general. In certain patients we are starting to use increasingly preoperative computed tomographic angiography to look at calcification and the burden of the ascending aorta. Unfortunately, with the VCSQI we are not able to comment on what some of the other centers are doing, but that is certainly an important point.

Dr James Brevig (Everett, Wash). I noticed that you had substantially higher blood use in your conventional CABG cases than in the OPCAB cases. I also noticed that many of the outcomes that we have been discussing in terms of mortality, length of stay, intubation time, and other complications are also associated with packed cell transfusion. What do you think your results would have looked like if you had a lower transfusion rate in your patients undergoing conventional CABG?

Dr LaPar. That is a very important point. I personally think that a major component to the prolonged ventilation occurring in our conventional CABG pump patients is likely influenced by that increased transfusion requirement and a transient acute lung injury that may have occurred as a result. That has been a focus of our basic science laboratory for many years, looking at that effect. If the transfusion requirements were to be decreased, we probably would not see as much of an influence on prolonged ventilation, and it may have helped make our overall morbidity among the 2 patient cohorts much more balanced. 